\title{
Estratégias de leitura e Literatura Infantil: uma proposta de atividade prática com o livro Menina bonita do laço de fita
}

\author{
Reading strategies and children's literature: a proposal of practical \\ activity with the Brazilian book Menina bonita do laço de fita
}

Talita Santana Maciel ${ }^{1}$

DOI: $10.28998 / 2317-9945.2020 n 65 p 59-70$

\section{Resumo}

Partindo da teoria bakbtiniana e dos pressupostos da psicologia Histórico-Cultural, considera-se que a literatura medeia a relação da criança com a cultura de seu tempo, e do movimento de apropriação que emerge no contato dessa criança com a obra surge um diálogo com a literatura, visto que a criança leitora atende à característica de incompletude dos enunciados, posicionando-se como o outro diante do texto e atribuindo sentidos a esse. Assim, é importante que o professor ensine as formas como o pequeno leitor em formação deve agir diante do texto (valendo-se de estratégias de leitura), de modo que esse leitor mirim estabeleça com a obra relações contextuais de natureza cultural, compreendendo o que lê, construindo sentidos e dialogando com o texto. Este artigo, fruto de pesquisa bibliográfica, tem como objetivo, portanto, apresentar uma proposta prática de leitura usando algumas estratégias de leitura a partir da obra intitulada Menina bonita do laço de fita, de Ana Maria Machado e Claudius Ceccon.

Palavras-chave: Literatura. Formação de leitores. Estratégias de leitura

\begin{abstract}
Based on bakbtinian theory and the assumptions of Historical Cultural psychology, it is considered that the literature mediates the child's relationship with contemporary culture, and from the movement of appropriation that emerges in the contact of this child with the book, a dialogue is born between the child and the literature, because as a reader, the child complete the utterances, positioning themselves as the recipient of the text and assigning meanings to it. Thus, it is important that the teacher teach the ways in which the student in formation should act in front of the text (using reading strategies), so that this reader establishes with the book contextual relations of cultural origin, understanding what he is reading, constructing meanings and dialoguing with the text. This article is a product of bibliographic research and aims to present a reading practice using some of the reading strategies from the book. Menina bonita do laço de fita, by Ana Maria Machado and Claudius Ceccon.
\end{abstract}

Keywords: Literature. Reader development. Reading strategies

Recebido em: 11/09/2019.

Aceito em: 06/11/2019.

\footnotetext{
${ }^{1}$ Doutoranda pelo Programa de Pós-graduação em Educação da Universidade Estadual Paulista Júlio de Mesquita Filho. Mestre e pedagoga pela mesma instituição.
} 


\section{Introdução}

Encontramos na Teoria Histórico-Cultural - cujo principal representante é Lev Semionovitch Vygotsky (1896-1934) - a importante constatação de que, diferente do psiquismo animal, o psiquismo humano é submetido às leis do desenvolvimento sóciohistórico: a origem das formas superiores de comportamento consciente está nas relações sociais que o ser humano estabelece com a realidade objetiva, visto que o desenvolvimento do pensamento acontece antes no plano social, como processo interpessoal e interpsicológico, para depois tornar-se individual, dessa vez como processo intrapessoal ou intrapsicológico. Nesse processo, o ser humano precisa apropriar-se da cultura acumulada, já que esta constitui a mediação entre a história de formação do gênero humano e a formação de cada indivíduo como um ser humano (DUARTE, 2007).

Nessa perspectiva, e considerando-se, também, a concepção bakhtiniana, Arena (2010) discute as relações entre literatura e cultura, destacando que a literatura medeia a relação da criança com a cultura de seu tempo, mas não se limita a ela: transcende o contexto cultural, tanto para o passado quanto para o futuro. Além disso, nesse enlace entre literatura e cultura, considera-se que a criança necessita de um contexto cultural para apropriar-se daquela cultura que está presente no gênero literário a que tem contato. No movimento de apropriação, a criança leitora atende à característica de incompletude dos enunciados, posicionando-se como o outro no diálogo com a literatura e apreende o modo de atribuição de sentidos em atitude própria de um ser outro.

Ainda de acordo com Arena (2010), é importante que se conceba a leitura como enunciado do outro, pois, desse modo, flui o movimento dialógico entre leitor, obra e autor, e surge a necessária compreensão do processo de leitura como atribuição de sentidos. A atividade de leitura é, portanto, compreender a palavra do outro, buscando, em atitude responsiva, uma relação dialógica com essa palavra, a qual permite, por sua vez, a apropriação da cultura humana como via ao aperfeiçoamento da consciência individual e coletiva.

Apoiados na perspectiva de Bakhtin, que se associa à Teoria Histórico-Cultural, Girotto (2015) e Arena (2012) consideram que a participação do pequeno leitor nesse movimento dialógico da leitura acarreta a sofisticação da consciência, uma vez que é ação direta na constituição de funções psíquicas superiores e, consequentemente, no contínuo processo de humanização.

Nesse contexto, ler para compreender, dialogar com o texto e construir sentidos é primordial. Nas palavras de Girotto (2013, p. 348): “[...] a leitura é dialogia, e somente ganha existência quando o leitor a produz na relação entre o que ele é, o que já sabe e conhece, e aquilo que o texto criado pelo outro está a ofertar". Assim, cabe ao professor ensinar as formas como o pequeno leitor em formação deve agir diante do texto, de modo que esse leitor mirim estabeleça com a obra relações contextuais de natureza cultural. É caminhando neste horizonte teórico que Girotto e Souza (2010) apresentam uma opção metodológica calcada no ensino de modos de ler: o uso de estratégias de leitura em sala de aula.

Diante de tais considerações iniciais, ressaltamos que o objetivo deste texto é apresentar uma proposta prática de leitura com o uso de algumas das denominadas estratégias de leitura, a partir da obra intitulada Menina bonita do laço de fita, de Ana Maria Machado e Claudius Ceccon. A escolha da obra se deu pela qualidade do projeto estético-literário desta, e pelo fato de que a narrativa envolve um tema de extrema importância, principalmente no contexto brasileiro: a questão da diversidade étnico-racial. De acordo com Candido (1995, p. 
186), com quem concordamos, a literatura associa-se aos direitos humanos duplamente: primeiro porque corresponde a uma necessidade universal que humaniza, liberta do caos. Segundo porque "pode ser um instrumento consciente de desmascaramento pelo fato de focalizar as situações de restrição dos direitos, ou de negação deles [...]"'. Assim, a obra Menina bonita do laço de fita é expressão material das palavras de Antonio Candido, tanto por sua notoriedade literária quanto por sua abordagem narrativa voltada a um dos princípios básicos propagados na luta em defesa dos direitos humanos: o respeito à diversidade.

Este texto foi organizado em três tópicos principais: no primeiro, apresentamos sumariamente a biografia da escritora Ana Maria Machado e do ilustrador Claudius Ceccon; no segundo, analisamos a obra em questão no que se refere aos paratextos, à linguagem escrita e à linguagem visual; no terceiro e último tópico, comentamos a metodologia de ensino pautada no uso das estratégias de leitura, de Girotto e Souza (2010), e expomos uma proposta de prática leitora destinada especialmente a crianças de 4 e 5 anos, que frequentam a educação infantil. A organização dos subtítulos foi pensada levando-se em consideração que o conhecimento sobre a estrutura da narrativa e sobre a relevância dos paratextos de uma obra é muito importante para o professor que deseja realizar seu trabalho na perspectiva apontada por este texto. Assim, para que o professor tenha condições de ensinar as crianças a utilizarem estratégias de compreensão daquilo que se lê, precisa, antes, realizar uma leitura aprofundada dos livros de Literatura Infantil com os quais irá trabalhar, identificando a estrutura e as características da obra como um todo.

\section{Sobre Ana Maria Machado e Claudius Ceccon}

Ana Maria Machado é considerada uma das mais versáteis e completas escritoras contemporâneas. Jornalista, professora universitária e pintora, a carioca criou suas primeiras histórias para a revista Recreio, em 1969, e não parou mais de escrever. Possui mais de 100 livros publicados (em 20 idiomas e 26 países) e mais de 20 milhões de exemplares vendidos. A escritora possui um site (www.anamariamachado.com) por onde é possível ter acesso à biografia, curiosidades sobre a vida e livros publicados por ela.

Ana Maria conquistou diversos prêmios ao longo de sua carreira, dentre eles o Prêmio Jabuti, por mais de uma vez; o Prêmio Machado de Assis da Academia de Letras para conjunto da obra; o Machado de Assis da Biblioteca Nacional para romance; o Casa de Las Américas; o Hans Christian Andersen nos anos 2000 - considerado o Nobel da literatura infanto-juvenil; o Príncipe Claus (Holanda); o Ibero-americano SM de Literatura infantojuvenil (2012); o Zaffari \& Bourbon (2013), por melhor romance do Biênio da Língua Portuguesa. Outras premiações marcaram a carreira de mais de 40 anos da escritora, como o Prêmio Bienal de SP; João de Barro; APCA; Cecília Meireles; O Melhor para o Jovem; O Melhor para a Criança; entre outros nacionais e internacionais.

A primeira edição da obra Menina bonita do laço de fita foi publicada em 1986 (também publicada em espanhol, inglês, francês, sueco, dinamarquês e japonês) e recebeu as seguintes premiações: Prêmio Bienal de São Paulo, em 1988 (menção honrosa como uma das cinco melhores obras do biênio); Prêmio Melhores do Ano, Biblioteca Nacional da Venezuela, em 1995; Altamente Recomendável, Fundalectura, Bogotá, Colômbia, em 1996; Melhor Livro Infantil Latino-americano, ALIJA - Buenos Aires, também em 1996 e Prêmio Américas (Melhores livros latinos nos EUA), em 1997. 
Claudius Sylvius Petrus Ceccon, ilustrador de Menina bonita do laşo de fita e, portanto, também compositor da obra, é artista gráfico, designer, ilustrador, arquiteto, jornalista, produtor de cinema e ativista político. Um gaúcho que vive no Rio de Janeiro desde os quatro anos de idade. Para conhecer melhor a história de Claudius, pode-se revisitar alguns dos mais importantes jornais e revistas alternativos brasileiros (Pif-Paf, O Pasquim, Caros Amigos) e, também, recorrer a uma série de siglas que acompanham sua carreira, dentre elas Idac (Instituto de Ação Cultural), Ibase (Instituto Brasileiro de Análises Sociais e Econômicas) e Cecip (Centro de Criação de Imagem Popular). No Idac, Claudius trabalhou com o pedagogo Paulo Freire; no Cecip, foi parceiro de Eduardo Coutinho e ajudou a realizar documentários como Santa Marta - Duas Semanas no Morro e Santo Forte.

Autor de vários livros, a maioria deles voltados para temas ligados à educação e à saúde, Claudius Ceccon teve suas obras como cartunista reunidas em Claudius, livro prefaciado por Jânio de Freitas e enriquecido com artigos de Millôr Fernandes, Cássio Loredano e Ferreira Gullar.

\section{Análise da obra: resumo, paratextos, linguagem escrita e linguagem visual}

O livro aqui discutido apresenta a história de uma linda menina negra que despertou a admiração de um coelho branco, e este passou a desejar ter uma filha tão pretinha quanto ela. O coelho perguntou à menina por quatro vezes, em tempos diferentes, qual o segredo para ter uma cor como a dela, mas ela não sabia a resposta, por isso inventou diferentes histórias nas três primeiras vezes: na primeira vez, inventou que caiu na tinta preta; na segunda vez, inventou que tomou muito café; e na terceira vez, inventou que comeu muita jabuticaba quando pequenina. O coelho seguiu todos os conselhos inocentes da menina, mas continuou branco. Ao ouvir a pergunta do coelho na quarta vez, a mãe da menina resolveu intervir e deu uma resposta: aquela linda cor viera de uma avó preta que a menina tinha. $\mathrm{O}$ coelho percebeu que a resposta fazia sentido e foi procurar uma coelha preta para se casar. Logo encontrou sua amada, uma coelha escura como a noite, e teve com ela uma ninhada de filhotes de cores diversas, inclusive uma coelhinha preta que se tornou afilhada da tal menina bonita do laço de fita.

O exemplar utilizado para análise possui 26 páginas no formato $22 \mathrm{~cm}$ x $19 \mathrm{~cm}$ e faz parte da oitava edição (terceira impressão), publicada em 2010 pela editora Ática, de São Paulo, como parte da coleção Barquinho de papel. A primeira edição da obra foi publicada em 1986 pela editora Melhoramentos e, em 1998, a editora Ática também passou a publicar exemplares.

Os paratextos nesse exemplar podem ser bem aproveitados pelos professores, visto que apresentam informações relevantes e que chamam a atenção, a começar pela capa. É importante que o professor auxilie as crianças a descobrirem os paratextos, isto é, os elementos do livro que não fazem parte diretamente da narrativa (como a capa, contracapa, folha de rosto, apresentação dos autores, por exemplo), encorajando as crianças a refletirem sobre como o livro é construído e sobre o fato de que os paratextos contêm elementos ricos, que podem acrescentar informações sobre a história e/ou ofertar pistas sobre qual é a temática ou o assunto de que trata o livro.

A capa de Menina bonita do laço de fita relaciona-se com a quarta capa, sendo que a lombada separa as ilustrações em tempos diferentes, mas dá continuidade às cores e 
elementos gráficos utilizados na parte superior do livro - elementos esses que visam a destacar o título da obra. Na capa aparece a menina (com muitos laços no cabelo) com o coelho, nitidamente admirado, enquanto na quarta capa há a ilustração do coelho saindo de uma lata de tinta preta. São ilustrações que podem ser bem exploradas pelo professor antes da leitura, principalmente porque o título da obra associa-se à ilustração da capa. A quarta capa é composta, também, por uma sinopse que convida o leitor a se debruçar sobre a história, pois apresenta a seguinte pergunta: "qual é, afinal, o misterioso segredo que a faz assim tão maravilhosa?” (MACHADO, 2010, p. 26). No verso da capa encontramos a ficha catalográfica e no verso da quarta capa há a identificação da coleção Barquinho de papel, com uma lista dos livros que a compõem.

Ainda na capa encontramos o título, centralizado na parte superior e em destaque, por meio de letras brancas sobrepostas a um fundo rosa. O título causa, propositalmente, um efeito de ritmo e sonoridade à leitura devido à utilização da rima, um recurso estilístico que costuma agradar às crianças. Dessa forma, a exploração do título antes da leitura da narrativa é, também, uma proposta de trabalho para o professor. Acima do título está o nome da autora e logo abaixo está o nome do ilustrador.

A folha de rosto apresenta a mesma ilustração da capa, mas é interessante observar a mudança no tamanho da fonte utilizada na escrita do nome da autora e do ilustrador: enquanto há diferenciação na capa, na folha de rosto a fonte é a mesma. Conforme discute Faria (2013), é importante que as crianças entendam que as ilustrações são constituintes do livro, em suas diferentes funções, portanto, é igualmente importante que haja valorização do ilustrador, tanto quanto do autor. $\mathrm{Na}$ folha de rosto está, ainda, o nome da editora.

Encontramos a apresentação dos autores na última página do livro, outro paratexto que pode ser bem aproveitado pelos professores. $\mathrm{Na}$ parte inferior desta página há a ilustração da menina com a coelhinha preta em seu colo, ambas usando laços de fita vermelhos.

Quanto à estrutura da narrativa, Faria (2013) apresenta um esquema básico tradicional que pode ser sintetizado da seguinte forma: situação inicial (equilíbrio), desenvolvimento (surgimento de um problema) e desenlace (desfecho). No caso, a obra Menina bonita do laço de fita obedece a essa estrutura. A cena inicial é marcada por um estado de equilíbrio, sem um problema, quando a narrativa apresenta as características da menina (personagem principal). A situação de desequilíbrio - que marca o desenvolvimento da história - surge quando o coelho começa a questionar a menina sobre sua cor e, a cada pergunta/problema, surge uma tentativa de resolução malsucedida por parte do coelho. Quando a mãe da menina resolve intervir, começa o desenlace da história: o coelho encontra uma resposta para seu questionamento e consegue ter uma filha pretinha como a menina que lhe causava admiração. Nesse caso, portanto, o desenlace é feliz e há recuperação do equilíbrio inicial.

Maria Alice Faria (2013) faz a seguinte afirmação:

O texto literário narrativo oferece ao leitor a possibilidade de "experimentar uma vivência simbólica" por meio da imaginação suscitada pelo texto escrito e/ou pelas imagens. A literatura [...] é portadora de um sistema de referências que permite a cada leitor organizar sua função psíquica com o vivido e a sensibilidade que lhe é própria. Tornar-se leitor de literatura é um vai-vem constante entre realidade e ficção que permite avaliar o mundo, se situar nele (FARIA, 2013, p. 19). 
Consideramos que a obra Menina bonita do laço de fita possui tais características literárias, uma vez que a história estimula a imaginação e instiga a curiosidade, de maneira bem-humorada e rica em detalhes. Destacamos o seguinte trecho a fim de demonstrar que a linguagem escrita desta obra traz elementos que possibilitam a vivência simbólica: "os cabelos eram enroladinhos e bem negros, feito fiapos da noite. A pele era escura e lustrosa, que nem pelo da pantera-negra quando pula na chuva" (MACHADO, 2010, p. 3).

Ainda sobre a linguagem escrita, vale ressaltar que a apresentação do texto no livro dá-se por meio do uso de letras maiúsculas e também minúsculas, ou seja, não é um livro que contém apenas letras maiúsculas como muitos dos livros que se destinam a crianças em fase de (pré)alfabetização e que partem da ideia equivocada de que a leitura é facilitada quando a criança vê no livro apenas letras em caixa alta. Afinal, ler vai muito além da decodificação. Ler é compreender, é atribuir sentidos, é colocar-se diante da obra como aquele que preenche as lacunas dos enunciados de acordo com o que é/sabe, em busca de se refazer, de se aperfeiçoar, não só enquanto leitor, mas enquanto ser humano.

A respeito da linguagem visual, Faria $(2013$, p. 38) ressalta que, em linhas gerais, texto escrito e ilustrações entrosam-se, completam-se: a ilustração destaca momentos significativos da história e facilita a compreensão pela criança, "enquanto o texto escrito dá mais detalhes sobre o que se passa, sem desviar a leitura das funções específicas do escrito e de seu componente literário". No entanto, as funções das ilustrações podem ser diversas, de acordo com o objetivo da obra e de acordo com a própria concepção do artista sobre a Literatura Infantil.

No que refere à obra aqui analisada, podemos dizer que as ilustrações cumprem com a função de marcar momentos significativos da narrativa, mas vão além, enriquecendo o conjunto da obra com elementos não explícitos no texto escrito. Faria (2013, p. 93) afirma que, em livros que apresentam textos de extensão média, como é o caso deste aqui analisado, "a ilustração tende a se afastar de suas funções [...] de complementaridade, colaborando com o escrito de formas variadas", em alguns momentos acrescentando detalhes, mas, sobretudo, colaborando com o todo da narrativa, sem necessariamente complementar o que o texto escrito não descreveu. O trabalho de Claudius Ceccon em Menina bonita do laço de fita caminhou neste sentido.

Sobre as características da linguagem visual em relação à linguagem escrita, vale observar o seguinte:

$\mathrm{Na}$ leitura da escrita, o olho percorre a linha impressa da esquerda para a direita e de cima para baixo, linha a linha, e a leitura se efetua pela trajetória do olhar. Mas, numa imagem, a trajetória do olhar não é linear: o olhar percorre a ilustração em diversas direções, orientadas pelas características da imagem. Nessa leitura, componentes da imagem são hierarquizados segundo a intenção do ilustrador e o olho é guiado por essa hierarquia (FARIA, 2013, p. 40).

Assim, é possível associar a forma como o ilustrador direcionou o olhar do leitor nesta obra a dois recursos de articulação entre texto escrito e texto imagético apresentados por Faria (2013): a utilização de várias ações em um só plano e o jogo das perspectivas.

O recurso de utilização de várias ações em um só plano fica visível principalmente nas páginas de 8 a 13. Nas páginas 8 e 9, por exemplo, há a ação do coelho de perguntar à menina qual o segredo para ser tão pretinha, a ação de mergulhar em um balde de tinta preta 
e a ação de tomar chuva. Quando a obra apresenta esse recurso, o professor pode conversar com as crianças sobre o que se passou, quando e onde, e exemplificar o aprisionamento do tempo pelo espaço, levando as crianças a perceberem que ilustrações que estão próximas umas das outras, ou até mesmo juntas, não se referem, necessariamente, a fatos que ocorreram no mesmo espaço físico e/ou em intervalos de tempo próximos e sucessivos (FARIA, 2013). O fundo branco que acolhe imagens em cores fortes auxilia na construção desse recurso da linguagem visual.

O outro recurso da linguagem visual verificável na obra, que é enriquecedor na leitura de imagens, é o jogo das perspectivas. Ele proporciona ao professor a possibilidade de explorar hipóteses em diálogo com as crianças (FARIA, 2013). Podemos citar a página 2, em que o desenho da menina negra ocupa todo o espaço, e atrás da menina está uma pantera negra com o corpo esticado, em posição de pulo. O ilustrador, propositalmente, deixou a imagem da menina em primeiro plano no espaço, escondendo parte da pantera negra atrás dela, uma vez que a pantera só aparece porque foi utilizada em uma comparação feita pela autora, e não porque representa uma personagem da história. O professor pode questionar, por exemplo, por que a ilustração da pantera é menor e está atrás (e não ao lado ou sobreposta), levando as crianças a perceberem a articulação entre ilustração e texto escrito.

O projeto gráfico do livro leva o leitor a observar texto escrito e texto imagético intercaladamente (mesmo leitores não alfabetizados). Ora as ilustrações aparecem primeiro na página, para só depois aparecerem frases e imagens intercaladas, ora a escrita aparece primeiro, seguida de uma sequência intercalada de imagens e frases. Esse estilo gráficoeditorial tornou a leitura mais dinâmica, levando os olhos a observarem a relação íntima na obra entre cenas marcadas por texto e cenas marcadas por ilustrações.

Enfim, em se tratando de Literatura Infantil, é preciso que o professor-mediador estimule a criança/jovem a compreender que a linguagem visual e a linguagem escrita imprimem elementos no encadeamento narrativo que precisam ser complementados pelas vivências do leitor, a fim de que a história seja lida por inteiro e imbuída de significados. É uma função que lida com exercícios no plano da percepção cognitiva, por isso com ações não mensuráveis, "mas que não significa ler pelo aluno ou fixar um determinado tipo de leitura: apenas auxiliá-lo a perceber os elementos mais aparentes da narrativa, para que ele venha a ler com autonomia não um determinado livro, mas diversos livros" (FARIA, 2013, p. 129).

\section{As estratégias de leitura: sugestões para a prática em sala de aula}

A proposta de trabalho com as estratégias de leitura surge dos estudos realizados por Girotto e Souza (2010), descritos no livro Ler e compreender: estratégias de leitura. As autoras partem de pesquisas de escritores norte-americanos, bem como de suas concepções sobre leitura e formação de leitores, e afirmam que o propósito do uso das estratégias de leitura é a interlocução com o texto e a construção do significado por parte do leitor mirim. Assim, o domínio das estratégias de leitura é um meio (e não um fim), é uma alternativa metodológica para que o professor ensine os alunos a compreenderem o que leem e para que os alunos se sintam motivados e interessados pela leitura de outros livros. A ideia é a de que cabe ao professor " [...] ofertar situações para que as crianças possam monitorar e ampliar o entendimento, bem como possam adquirir e ativar o seu conhecimento de mundo, linguístico e textual, a partir do que estão lendo" (GIROTTO; SOUZA, 2010, p. 55). 
O conjunto de estratégias de leitura é composto por: conexões, inferência, visualização, questionamento, sintese e sumarização. É importante destacar que tais estratégias são mobilizadas conjuntamente no ato de ler e não há uma ordem ou sequência para o ensino das estratégias. O trabalho pode ser organizado segundo a faixa etária e as especificidades do grupo de alunos com o qual o professor irá trabalhar.

Conforme Girotto e Souza (2010), as atividades relacionadas a esse ensino podem iniciar na educação infantil, com crianças ainda não alfabetizadas, uma vez que é por meio da inserção na linguagem escrita - com todas as suas características específicas e concebida como constituinte da cultura humana a ser apropriada pelos homens - que as crianças aprendem e se desenvolvem. Dessa forma, a atividade prática discutida neste texto foi pensada para crianças de 4 a 5 anos, está voltada ao trabalho com as conexões e com a inferência e apresenta adaptações quanto ao ensino proposto no capítulo escrito por Cyntia G. G. S. Girotto e Renata J. de Souza.

Fazer conexões entre a leitura e as experiências/vivências pessoais facilita $\mathrm{o}$ entendimento. É fundamental que os professores ensinem as crianças a ativarem seus conhecimentos prévios (antes, durante e/ou após a leitura), para que elas pensem sobre suas conexões, sejam elas conexões com episódios de sua própria vida (do tipo texto-leitor), com outros textos (texto-texto) ou com acontecimentos mais globais, como da cidade, país, ou mundo em que o leitor vive (texto-mundo). Nas palavras de Girotto e Souza (2010, p. 6768), "o propósito de fazer conexões é aumentar o entendimento para que o pensamento da criança não escape para outras áreas completamente alheias ao texto".

Já a inferência torna-se fundamental na compreensão do que se lê porque requer conclusões e/ou interpretações acerca daquilo que não está explícito no texto. Como afirmam Girotto e Souza (2010, p. 76): “os escritores não expressam todos os seus pensamentos em uma página, mostram, paulatinamente, uma ideia por vez até que o leitor possa fazer uma inferência apropriada sobre o tema do texto ou uma dedução sobre o que está por vir". Dessa maneira, os professores ensinam as crianças a combinarem seus conhecimentos prévios com as dicas que o texto possui, para que façam inferências adequadas e criem expectativas sobre o que está por vir, em situação de diálogo com o texto. Trata-se de questionar, deduzir, prever, levantar hipóteses.

Os conhecimentos prévios que as crianças trazem para a leitura sustentam todos os aspectos da aprendizagem e do entendimento. Sugerimos, portanto, que o professor inicie o trabalho com o livro Menina bonita do laço de fita antes de apresentar de fato o livro, ou seja, o professor pode organizar uma sequência de atividades prévias que auxiliarão, mais tarde, na ativação das conexões, especialmente as do tipo texto-leitor. Propomos um trabalho com as famílias, as árvores genealógicas e a construção/valorização da identidade da criança. $O$ professor pode aproveitar a exploração da autoimagem para ressaltar as diferenças entre os seres humanos e, principalmente, o respeito que é necessário que se tenha em relação às diversidades.

Esse trabalho prévio se justifica por pelo menos dois motivos: o primeiro deles é de que, como já citado, quanto maior é a bagagem de experiências que a criança carrega, maior será a chance de realização de conexões que levem-na ao entendimento e à atribuição de sentidos à leitura, além do interesse para a leitura de novos livros; o segundo motivo é que o livro gira em torno de um tema de extrema importância no contexto brasileiro (a diversidade étnico-racial) e, na concepção de Girotto e Souza (2010), com a qual concordamos, é importante que a criança busque os sentidos do texto, as mensagens que o(a) autor(a) 
pretende deixar, para que depois possa formar opiniões e articular as ideias centrais do livro com as suas próprias opiniões. Essa busca pelos sentidos principais de um texto refere-se, inclusive, à estratégia de leitura denominada sumarização ${ }^{2}$. Realizar um trabalho consistente sobre identidade, famílias e diversidades antes da leitura pode auxiliar na compreensão das ideias principais da narrativa.

Quando o professor for realizar a leitura do livro para/com as crianças, pode organizar primeiro um trabalho mais voltado à inferência. Conforme os estudos de Girotto e Souza (2010), o professor pode gerar situações para que as crianças possam inferir o significado de palavras desconhecidas, como pode, também, propor situações para inferências pelos paratextos e pela narrativa.

Assim, essa atividade prática pode ter início com a exploração dos paratextos (conversar sobre autora e ilustrador, função e informações da ficha catalográfica, sobre premiações que o livro recebeu e sobre a coleção da qual o livro faz parte, por exemplo). Os momentos de questionamentos por parte do professor são muito importantes na leitura compartilhada, pois o professor verbaliza seus pensamentos enquanto lê, com o objetivo de mostrar como raciocina com o uso da estratégia, e ensina as crianças a ler, tornando explícito aquilo que ainda está implícito para a criança (GIROTTO; SOUZA, 2010). Sugerimos algumas perguntas iniciais: por que este coelho da capa está olhando para a menina desta forma? Ela é a menina bonita de que fala o título? Por que na quarta capa aparece outro coelho saindo de uma lata de tinta preta? Ou será o mesmo coelho da capa? O que será que ele queria fazer?

Não só no momento de exploração dos paratextos, mas também durante toda a leitura da história o professor pode elaborar perguntas ao texto com a participação das crianças, incentivando-as a inferir, isto é, antecipar informações, chegar a uma grande ideia, deduzir um resultado etc. De acordo com os estudos de Faria (2013, p. 115), "os alunos devem ser ouvidos em suas interpretações muitas vezes diversas, pois os textos de ficção facultam certa liberdade para a leitura”, assim, o professor deve deixar que as crianças se expressem durante a leitura da história, de maneira a não engessá-las pelas questões propostas somente por ele.

Ao longo da leitura o professor pode oportunizar às crianças a fala, expressão de opiniões, hipóteses, previsões, conexões e, desta maneira, avaliar o desenvolvimento da atividade desde o início, comparando-a a outras já realizadas nessa direção, pois a tendência é a de que esse trabalho, depois de um tempo, propicie uma ampliação de repertório cultural às crianças, as quais melhorarão a ativação de conhecimentos prévios e, consequentemente, o processo de estabelecimento de conexões.

Antes de sugerirmos outros questionamentos que podem ser levantados na leitura do livro Menina bonita do laço de fita, faremos o seguinte apontamento sobre a linguagem visual: conforme afirma Faria (2013), a leitura de uma ilustração vai muito além da mera apreensão denotativa do que está representado. Cabe ao professor proporcionar aos seus alunos o aguçar dos olhos, de tal modo que o olhar possa apreender todos os elementos constitutivos da imagem, atribuindo-lhe sentido. Nessa direção, o professor pode aproveitar mais as ilustrações dos livros ao trabalhar com a inferência na educação infantil (sem relegar a segundo plano o texto escrito), aproveitando para educar o olhar das crianças no que refere ao texto imagético. Na página 7, por exemplo, o professor pode perguntar aos alunos: o que

2 A estratégia de sumarização corresponde à busca pela(s) ideia(s) central(is) de um texto. Sumarizar é, pois, identificar as principais mensagens sublinhadas pelo(a) autor(a). 
a menina estava fazendo enquanto o coelho a admirava? Onde será que ela estava? Na página 8, 10 ou 12 é possível perguntar: e agora que o coelho veio conversar com a menina, o que vocês acham que ela estava fazendo e onde ela estava? $O$ professor pode planejar previamente as perguntas de maneira que elas sejam alteradas de ilustração para ilustração, levando as crianças a perceberem a mudança de tempo e espaço na narrativa.

Com relação ao texto escrito no trabalho com a estratégia inferência, o professor pode utilizar, por exemplo, a pergunta feita pelo próprio coelho: menina bonita do laço de fita, qual é teu segredo para ser tão pretinha? O que vocês acham que ela irá responder? Qual é o segredo da menina? Pode-se aproveitar, também, as respostas dadas pela menina para questionar. Como exemplo: ela disse que é pretinha porque caiu na tinta preta quando pequenina... Vocês acham que o coelho irá seguir esse conselho para tentar ficar pretinho também? Nesse momento, pode ser que as crianças se lembrem da ilustração do coelho na quarta capa.

Embora tenhamos sugerido que a primeira leitura do texto seja feita com um foco maior na estratégia inferência, se alguma criança expressar suas conexões ao longo da leitura o professor deve anotá-las de maneira rápida e incentivar o estabelecimento de outras. Ao término da leitura, sugerimos que o professor retome a história com os alunos, retome as conexões já anotadas e peça que eles falem sobre coisas de que se lembraram ao verem uma ilustração ou ao escutarem uma frase durante a leitura oral do texto feita pelo professor. Ao ler o texto para as crianças, o próprio professor pode falar sobre as coisas de que se lembrou, como uma forma de estímulo.

Cyntia G. G. S. Girotto e Renata J. de Souza apresentam a proposta de que haja, nesse momento, a construção coletiva de um cartaz contendo as conexões das crianças. Nesse caso, julgamos mais adequada a elaboração de um cartaz com conexões do tipo textoleitor, como demonstra a figura a seguir. Nas palavras das referidas autoras, "o cartaz ajudará os alunos a ter uma ideia geral das várias leituras feitas em sala de aula por seus colegas, ampliando, assim, as conexões" (GIROTTO; SOUZA, 2010, p. 73).

Figura 1 - Quadro representativo de um cartaz com ênfase na conexão texto-leitor

\section{Cartaz: conexão texto-leitor}

Após a leitura do livro Menina bonita do laço de fita, de Ana Maria Machado, lembrei-me de que:

Fonte: autora deste artigo.

As estratégias de leitura denominadas conexões e inferência foram escolhidas neste caso devido à faixa etária selecionada para a sugestão de atividade prática e devido às características do livro selecionado. Porém, outras estratégias podem ser exploradas desde a educação 
infantil, em especial à visualização ${ }^{3}$, e é preciso destacar que a proposta materializada neste texto é apenas uma dentre as inúmeras possibilidades de trabalho com a Literatura Infantil na formação de leitores.

\section{Considerações finais}

A intenção deste trabalho foi a de demonstrar que um livro de Literatura Infantil pode ser explorado em todos os seus aspectos, desde a capa, paratextos, linguagem escrita e visual. Sobretudo, pretendemos deixar claro que o trabalho com as estratégias de leitura é importante na medida em que permite ao leitor ampliar e modificar seus processos mentais para compreender não só textos, mas o próprio ambiente cultural em que vive e está inserido, e o papel do professor nesse trabalho é o de criar elos de mediação entre a criança e o livro.

Esperamos que este texto possa contribuir e motivar outros profissionais para que mais pessoas envolvidas com a área da educação compreendam a formação de leitores não enquanto mero processo de decodificação, mas sim enquanto processo essencial à humanização. Conforme afirma Arena:

$\mathrm{O}$ ato de ler, como uma experiência cultural, desde sua aprendizagem até os limites do leitor sênior [...], configura o pensamento humano e se reconfigura ao longo da história como ato herdado e legado pelos homens às gerações que se sucedem. Desse modo, o pequeno leitor não aprende a ler como aprendera a geração que a ele lega o ato de ler, mas o aprende, como cultura rearranjada e transmitida pela mesma geração que alterou e foi alterada pela ação de ler (ARENA, 2010, p. 35).

Fica claro, pois, que o exercício de ler carrega traços da cultura acumulada por toda a humanidade, mas se transforma a cada geração, constituindo-se enquanto exercício mutável, e, exatamente por isso, enquanto ato cultural. A leitura muda o homem e este, por sua vez, pode alterar o processo de mediação de leitura, transformando muitos outros homens, rumo à humanização.

\section{Referências}

ARENA, D. B. A literatura infantil como produção cultural e como instrumento de iniciação da criança no mundo da cultura escrita. In: MENIN, A. M. da C. S. et al. (Org.) Ler e compreender: estratégias de leitura. Campinas: Mercado de Letras, 2010. p. 13-44.

ARENA, D. B. Dilemas didáticos sobre as ações de ensinar a ler. In: AZEVEDO, F.; SOUZA, R. J. Gêneros textuais e práticas educativas. Lisboa, Porto: Lidel, 2012.

CANDIDO, A. O direito à literatura. In: CANDIDO. Vários escritos. 3. ed. São Paulo: Duas Cidades, 1995. p. 186-263.

\footnotetext{
${ }^{3}$ Esta estratégia de leitura diz respeito às imagens mentais que são criadas no decorrer da narrativa. Visualizar é uma forma de inferir que permite a atribuição de sentidos e significados por meio das imagens e representações mentais criadas a partir do texto.
} 
DUARTE, N. Educação Escolar, teoria do cotidiano e a escola de Vygotsky. 4. ed. São Paulo: Autores Associados, 2007.

FARIA, Maria Alice. Como usar a literatura infantil na sala de aula. São Paulo: Contexto, 2013.

GIROTTO, C. G. G. S. Reflexões sobre a formação do leitor mirim: leitura, literatura infantil e biblioteca escolar. Ensino Em Re-Vista, v. 20, n. 2, p. 341-356, jul./dez. 2013. Disponível em:

<http://www.seer.ufu.br/index.php/emrevista/article/view/23711/13046>. Acesso em: 09 dez. 2019.

GIROTTO, C. G. G. S. Literatura na infância: a criança, o livro e capacidade de ler. Nuances: estudos sobre Educação, Presidente Prudente, v. 26, n. 3, p. 34-52, set./dez. 2015. Disponível em: <http://revista.fct.unesp.br/index.php/Nuances/article/view/3745/3146>. Acesso em: 09 dez. 2019.

GIROTTO, C. G. G. S.; SOUZA, R. J. de. Estratégia de leitura: para ensinar alunos a compreender o que leem. In: MENIN, A. M. da C. S. et al. (Org.). Ler e compreender: estratégias de leitura. Campinas: Mercado de Letras, 2010. p. 45-113.

MACHADO, A. M. Menina bonita do laço de fita. Ilustrações de Claudius. 8. ed. São Paulo: Ática, 2010. 